\title{
Hemodynamic Correlates of Arterial Compliance
}

\author{
James J. Ferguson, III, MD, and Otelio S. Randall, MD \\ There is at present no good understanding of the exact clinical correlates of arterial \\ compliance. The purpose of this study was to establish which hemodynamic variables \\ are most strongly associated with compliance. Hemodynamic measurements were per- \\ formed on 41 patients undergoing diagnostic cardiac catheterization. Cardiac outputs \\ were determined by thermodilution, and pressures were measured in the ascending \\ aorta with a catheter-tip manometer. Compliance was calculated from a mono-exponen- \\ tial fit of diastolic decay pressures. Pulse pressure(PP), stroke volume(SV), age, systolic \\ blood pressure(SBP), and cardiac output(CO) were significantly related to compliance. \\ The quotient SV/PP was a good estimate of compliance, as was a first-order function of \\ both SV and PP. There appear to be specific clinical correlates of arterial compliance, \\ as well as ways to estimate arterial compliance on the basis of conventional hemody- \\ namic measurements when direct calculations are not possible.
}

Key words: systolic blood pressure, age, pulse pressure, stroke volume

\section{INTRODUCTION}

Compliance is defined as the change in volume per unit change in pressure or the inverse of the slope of the pressure-volume relationship. Arterial compliance is a quantitative measure of the distensibility of the arterial system. Pressure-volume curves are a mainstay of in vitro measurement of compliance, but they are not presently applicable to the intact arterial system of a patient at the bedside. Current in vivo estimates of arterial compliance in humans and animals include pulse wave velocity [1-4], stroke volume divided by pulse pressure[1,5], indirect techniques using pressure-diameter relationships[6-10], as well as compliance as calculated from a monoexponential or multiple exponential (with or without a zero asymptote)[11-14], as qualitatively derived from stroke volume-pulse pressure relationships[15,16], and as described by more complex pressure-volume relationships.

Yet the clinical significance of compliance, regardless of how it is measured, has received little attention $[1,12,14-17]$ and thus remains imprecisely defined. The purpose of this study was to determine those conventional hemodynamic measurements most strongly associated with arterial compliance as calculated from a monoexponential decay model. Our hypothesis was that there would be easily measured hemodynamic parameters such as stroke volume and pulse pressure that would correlate with compliance.

\section{METHODS}

The experimental subjects were 41 patients, 27 men and 14 women, with ages ranging from 24 to 82 years (mean SD $=54.0 \pm 12.8$ ). These were subjects selected from a large group of patients undergoing diagnostic cardiac catheterization because of chest pain thought to be secondary to atherosclerotic coronary artery disease or possibly valvular or congenital heart disease. Appropriate informed consent was obtained for each catheterization. Patients found to have valvular heart disease, congenital heart disease, central or peripheral shunts, arrhythmias, or unstable angina pectoris were excluded. All data were obtained prior to the injection of contrast material. All pressures were measured with a cathetertip manometer (Millar, PC-350) advanced into the ascending aorta from a femoral artery. Cardiac outputs were measured by the thermodilution technique with a pulmonary artery catheter. The pressure data were recorded with an FM tape recorder (Hewlett-Packard, model $3964 \mathrm{~A}$ ) and subsequently digitized at 200 samples per second. The digitized data analyzed interactively with a computer (Digital Equipment Corporation, PDP-1160)

From the University of Michigan Medical Center, Ann Arbor, Michigan.

Received February 5, 1986; revision accepted July 14, 1986.

Preliminary reports of portions of the study were presented at the Annual Scientific Session of the American Heart Association in Anaheim, California, November 1983.

James J. Ferguson's current address and title are Assistant in Medicine, Cardiovascular Division, Beth Israel Hospital, 330 Brookline Avenue, Boston, MA 02215.

Address reprint requests to Otelio S. Randall, MD, Director, Coronary Care Unit and Hypertension Section, Department of Internal Medicine (Division of Cardiovascular Diseases), Howard University Hospital, 2041 Georgia Avenue, N.W., Washington, D.C. 20060. 
and graphics display (Tektronix, model 4010), using software specifically written for our curve-fitting techniques.

In our analyses, we treated diastolic decay, the arterial pressure between the dicrotic notch and diastolic blood pressure, as a monoexponential of the form $\mathrm{P}(\mathrm{t})=$ $P_{0}{ }^{-t / R C}$, where $P o$ is the initial pressure measured at the onset of the diastolic decay and $P$ is the pressure measured at each instant in time ( $t)$ during the decay $[11,13,14]$. In this model, the product $\mathrm{R} \times \mathrm{C}$ (resistance times compliance) equals Tau, the decay time constant of the three-element Windkessel [18], which can be obtained by a first-order (linear equation) fit of the $\log$ (pressure) versus time curve during diastolic pressure decay. Only exponential fits with a correlation coefficient of $\geqslant 0.95$ and statistical significance $(P<0.05)$ were used. Total peripheral resistance, the equivalent of $R$ in the model, was calculated from the ratio of mean pressure to cardiac output, and compliance was then calculated by dividing Tau by total peripheral resistance.

\section{RESULTS}

The sample means for our hemodynamic variables are summarized in Table I. We performed linear regression analysis and found that five of our measurements: age, systolic blood pressure, pulse pressure, stroke volume and cardiac output were significantly correlated with compliance. The former three had a negative correlation, while the latter two had a positive correlation. The strengths of the correlations are shown in Figure 1. Pulse pressure was the variable most strongly associated with compliance, followed in descending order by stroke volume, age, systolic blood pressure, and cardiac output. Sex, mean blood pressure, diastolic blood pressure, and heart rate were not significantly related to compliance.

If pulse pressure and stroke volume, the two most strongly associated variables are held constant by partial correlative analysis[19], the other previously related variables, namely age, systolic blood pressure, and cardiac output, lose their significant relationship with compliance. If age, cardiac output, and systolic blood pressure are in turn held constant by partial correlative analysis, stroke volume and pulse pressure remain significantly

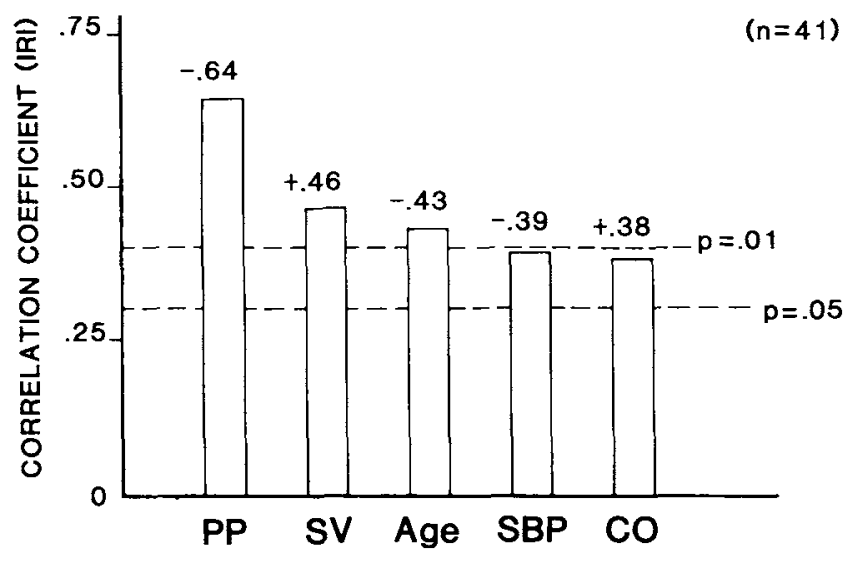

Fig. 1. Absolute value of correlation coefficient ( $r$ ) of variables related to compliance. $\mathrm{CO}$, cardiac output; PP, pulse pressure; SBP, systolic blood pressure; SV, stroke volume.

related to compliance. Stroke volume over pulse pressure was also strongly related to compliance. Figure 2 shows the regression line for this ratio $(r=0.80, p<0.001)$. We also arrived at a first-order function of both stroke volume and pulse pressure as an alternative estimate of compliance. The regression line for this relationship is shown in Figure $3(r=0.83, p<0.0001)$.

\section{DISCUSSION}

There are at present a number of techniques to estimate arterial compliance. Probably the oldest is pulse wave velocity, which has been used for over a century [2-4]. However, it does have distinct limitations in its application. It only estimates point-to-point or local compliance, the compliance of an arterial compartment bounded by fixed end points. The pulse wave velocity also increases distally in the smaller vessels and is to some extent influenced by pressure. Local arterial disease can alter pulse wave velocity, and controlling for variation in the peripheral circulation is extremely difficult. Messerli and co-workers[1], among others, have shown pulse pressure over stroke volume to correlate with pulse wave velocity. Conversely, stroke volume over pulse pressure will be

TABLE I. Range and Mean Hemodynamic Data for All Subjects $(n=41)$

\begin{tabular}{|c|c|c|c|c|c|c|c|c|c|c|c|}
\hline & \multicolumn{4}{|c|}{ Range and mean $(\mathrm{mmHg})$} & \multirow{2}{*}{$\begin{array}{c}\mathrm{CO} \\
(\mathrm{L} / \mathrm{min})\end{array}$} & \multirow{2}{*}{$\begin{array}{c}\text { TPR } \\
(\mathrm{mmHg} / \\
(\mathrm{ml} / \mathrm{sec}))\end{array}$} & \multirow{2}{*}{$\begin{array}{c}\mathrm{HR} \\
(\mathrm{bpm})\end{array}$} & \multirow{2}{*}{$\begin{array}{l}\text { SV } \\
(\mathrm{ml})\end{array}$} & \multirow{2}{*}{$\begin{array}{l}\text { TAU } \\
(\mathrm{sec}) \\
\end{array}$} & \multicolumn{2}{|c|}{$\begin{array}{c}\text { Range and Mean } \\
(\mathrm{ml} / \mathrm{mmHg})\end{array}$} \\
\hline & SBP* & DBP & PP & MBP & & & & & & SV/PP & $\mathrm{C}$ \\
\hline Range & $\begin{array}{l}92 \\
-204\end{array}$ & $\begin{array}{l}49 \\
-97\end{array}$ & $\begin{array}{l}26 \\
-132\end{array}$ & $\begin{array}{l}76.4 \\
-140\end{array}$ & $\begin{array}{l}3.3 \\
-8.6\end{array}$ & $\begin{array}{l}0.59 \\
-2.27\end{array}$ & $\begin{array}{l}51 \\
-105\end{array}$ & $\begin{array}{l}48.8 \\
-122.5\end{array}$ & $\begin{array}{l}0.77 \\
-1.97\end{array}$ & $\begin{array}{l}0.62 \\
-3.18\end{array}$ & $\begin{array}{l}0.54 \\
-2.30\end{array}$ \\
\hline $\begin{array}{l}\text { Mean } \\
\pm \text { SD } \\
\end{array}$ & $\begin{array}{l}126.9 \\
\pm 24.4 \\
\end{array}$ & $\begin{array}{l}70.7 \\
\pm 12.1 \\
\end{array}$ & $\begin{array}{l}56.2 \\
\pm 20.8 \\
\end{array}$ & $\begin{array}{l}94.4 \\
\pm 14.2 \\
\end{array}$ & $\begin{array}{l}5.7 \\
\pm 1.2 \\
\end{array}$ & $\begin{array}{l}1.05 \\
\pm 0.30 \\
\end{array}$ & $\begin{array}{l}73.9 \\
\pm 13.3 \\
\end{array}$ & $\begin{array}{l}78.4 \\
\pm \quad 18.5 \\
\end{array}$ & $\begin{array}{l}1.33 \\
\pm 0.34 \\
\end{array}$ & $\begin{array}{l}1.55 \\
\pm 0.59 \\
\end{array}$ & $\begin{array}{l}1.34 \\
\pm 0.41 \\
\end{array}$ \\
\hline
\end{tabular}

*SBP, systolic blood pressure; DBP, diastolic blood pressure; PP, pulse pressure; MBP, mean blood pressure; CO, cardiac output; TPR, total peripheral resistance; HR, heart rate (beats per minute); SV, stroke volume; TAU, arterial diastolic pressure decay time constant; C, arterial compliance. 


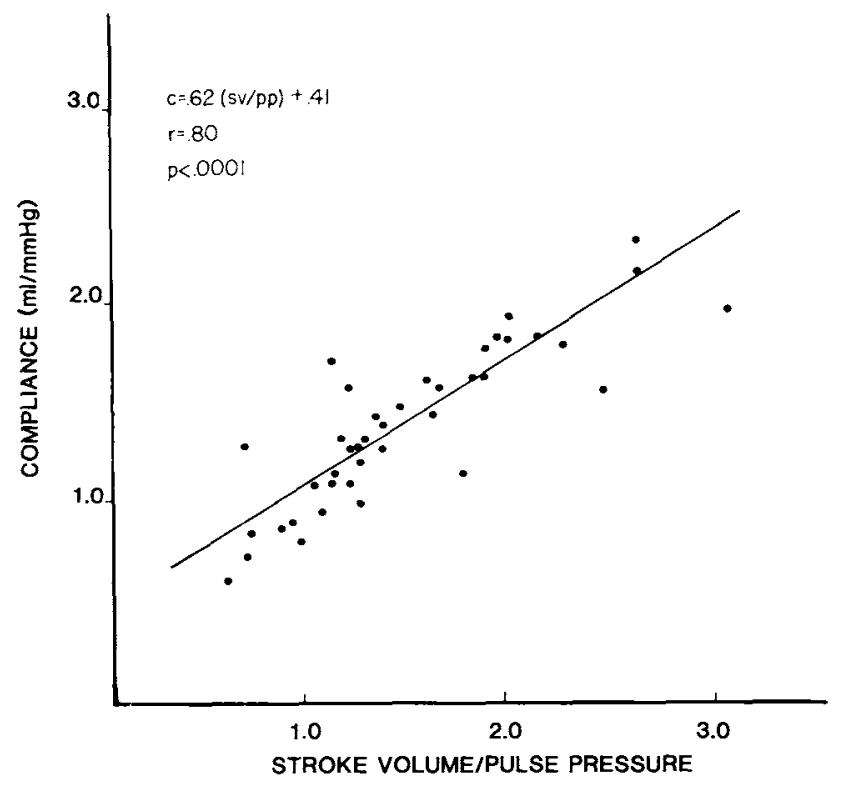

Fig. 2. Regression line for calculated compliance and stroke volume divided by pulse pressure (SV/PP).

inversely correlated with pulse wave velocity and should be directly related to compliance.

Unfortunately, the relationship of stroke volume to pulse pressure is theoretically variable with different states of compliance. A system with infinitely high compliance would be expected to have no relationship between the two variables. At the other extreme, an infinitely stiff system would have a direct relationship between stroke volume and pulse pressure[20]. This changing relationship over the continuum of compliance can be used to measure qualitatively compliance[17], but it also means that stroke volume over pulse pressure is not a linearly scaled estimate of compliance at extremes of the continuum. Our work has shown that within the pathophysiological range of pressure of our particular sample, stroke volume over pulse pressure is a good estimate of compliance as calculated from a monoexponential decay model. It is important to keep in mind that it is not stroke volume over pulse pressure alone, but a first-order or linear function of stroke volume over pulse pressure that is so strongly related to compliance, as shown by the nonzero intercept of the regression line. The strong pulse pressure-compliance association is not only due to an increase in systolic pressure with decreasing compliance, but also due to a tendency for diastolic pressure to decrease as compliance decreases[21].

The crucial issue, however, is what high or low arterial compliance means clinically, and how it can be assessed with the hemodynamic data usually available in the typical clinical setting. It was determined that it is possible to estimate roughly arterial compliance from routine

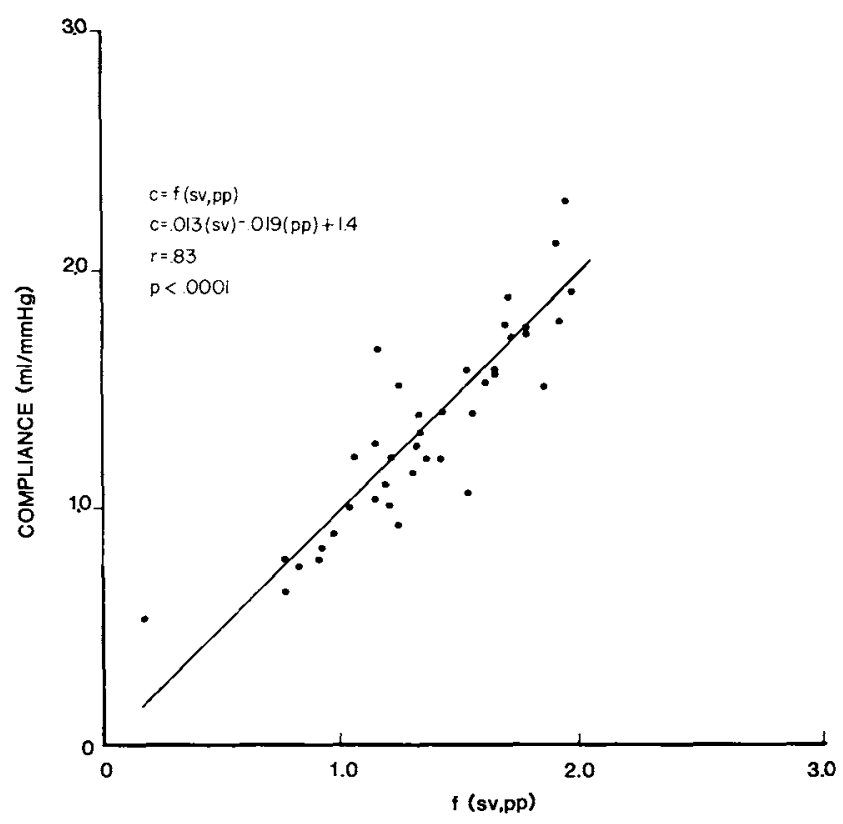

Fig. 3. Regression line for calculated compliance and a firstorder function of stroke volume and pulse pressure (f[SV,PP]).

hemodynamic measurements, either from a first-order function of the quotient stroke volume divided by pulse pressure, or from a first-order function of both stroke volume and pulse pressure. Our results indicate that low pulse pressure, high stroke volume, low systolic blood pressure, high cardiac output, and a younger age are associated with high compliance; the converse is also true; that is, low compliance is associated with aging, high pulse pressure, systolic pressure, and low stroke volume or cardiac output.

We would argue against the routine use of stroke volume or pulse pressure alone, or the use of regression equations for these variables to estimate compliance, since there are several conditions such as shunts and anemia that could produce either a large stroke volume or pulse pressure or both. However, the stroke volumepulse pressure ratio should give a reasonably good estimate of the arterial system compliance if the aortic valve is competent. In this situation the change in arterial pressure for a given stroke volume should be independent of ventricular function, and related to arterial compliance and peripheral resistance as in the Windkessel model.

In our sample, with stroke volume and pulse pressure held constant, age, systolic blood pressure, and cardiac output were not related to compliance. This might suggest that the influence of age, systolic blood pressure, and cardiac output on compliance are expressed through stroke volume and pulse pressure, but such an inference is not warranted on the basis of the present data. Previous 
studies have reported an increase[3,22-26], a decrease[27,28], or little change[29] in arterial stiffness with age, but this has been in a number of species, with varied techniques, looking at different vessels. Furthermore, it has been observed that systolic blood pressure does not increase with age in all populations[30]; nor do all arterial systems lose their compliance with aging[31].

In a monoexponential RC model, compliance is by definition inversely proportional to total peripheral resistance. It is no surprise, therefore, that cardiac output is related to compliance. Interestingly, mean pressure was not related to compliance, and even with cardiac output held constant by partial correlative analysis, stroke volume remained related to compliance. We noted that pulse pressure $(r=-0.64)$ had a slightly stronger relationship with compliance than total peripheral resistance $(r=-0.61)$, which was used in the actual calculation of compliance.

Our present study was not designed to investigate the hemodynamic sequallae of changing compliance from one level to another. Instead, we have measured compliance in a given physiopathopharmacological steady state and attempted to identify those routine hemodynamic variables most strongly associated with it. We have documented how well variables such as pulse pressure, stroke volume, and the stroke volume-pulse pressure ratio correlate with compliance determined from the time constant as derived from RC model theory. We have not attempted to establish normal arterial compliance values for sex and age, since the number of subjects was small, some patients had hypertension and/or coronary artery disease, and since they were receiving a variety of medical therapies. Since arterial compliance is a component of input impedance and has been shown to have a significant acute effect on ventricular function and blood pressure independent of peripheral resistance[14], it may be an important variable in certain clinical situations. The stroke volume to pulse pressure ratio appears to be a simple technique that provides useful clinical information about arterial compliance as previously suggested $[1,5,17]$. However, routine clinical use of this technique can not be recommended until more data on its sensitivity and specificity are available.

In summary, we make the following conclusions:

1) The variables that we found to be related to compliance as calculated from a monoexponential RC model include stroke volume, pulse pressure, age, cardiac output, and systolic blood pressure. We found sex, mean blood pressure, diastolic blood pressure, and heart rate to be unrelated to compliance.

2) Pulse pressure is the single measurement most strongly associated with arterial compliance.

3) Stroke volume and pulse pressure are correlated with compliance independently of other variables such as age, systolic blood pressure, and cardiac output.
4) Stroke volume over pulse pressure as an estimate of compliance correlates well with compliance determined from the decay time constant to the peripheral resistance ratio.

5) Stroke volume over pulse pressure appears to be a relatively good estimate of arterial compliance.

\section{REFERENCES}

1. Messerli FH, Ventura H, Aristimuno GG, Dreslinski GR, Frohlich ED: Arterial compliance in systolic hypertension. Clin Exp Hypertens [A] A4(7): 1037-1044, 1982.

2. Moens AI: Die Pulskurve. Leiden:Brill EJ, 1878(as cited in Burton, AC and second ed) "Physiology and Biophysics of the Circulation." Chicago:Year Book Medical Publishers, Inc., pp 160-166, 1972.

3. Hallock P: Arterial elasticity in man in relation to age as evaluated by the pulse wave velocity method. Arch Int Med 54:770$798,1934$.

4. Steele JM: Interpretation of arterial elasticity from measurements of pulse wave velocity. Am Heart J 12:452-465, 1937.

5. Tarazi RC, Magrini F, Dustan HP: The role of aortic distensibility in hypertension. In Miller P, Safar MD (eds): "International Symposium on Hypertension." Monaco: Boehringer Ingelheim, 1975, pp 133-145.

6. Luchsinger PC, Sachs M, Patel DJ: Pressure radius relationship in large blood vessels of man. Circ Res 11:885-888, 1962.

7. Remington JW: Pressure diameter relations in the in-vivo aorta. Am J Physiol 203:440-448, 1962.

8. Pieper HZ, Paul LT: Response of aortic smooth muscle studied in intact dogs. Am J Physiol 217:154-160, 1969.

9. Patel DJ, DeFreitas FM, Greenfield JC, Fry DL: Relationship of radius to pressure in the aorta of living dogs. J Appl Physiol 18:1111-1117, 1963.

10. Gerova M, Gero J: Range of sympathetic control of the dog femoral artery. Circ Res 24:349-359, 1969.

11. Randall OS, Ferguson JJ: Improved techniques for measuring arterial compliance: A preliminary report. J Hypertens 1(suppl 2):272-274, 1983

12. Simon AC, Safar MA, Levenson JA, Kheder AM, Levy BI: Systolic hypertension: Hemodynamic mechanism and choice of antihypertensive treatment. Am J Cardiol 44:505-511, 1979.

13. Eng C, Jentzer JH, Kirk ES: The effect of coronary capacitance on the interpretation of diastolic pressure-flow relationships. Circ Res 50:334-341, 1982.

14. Randall OS, van den Bos GC, Westerhof N: Systemic Compliance: Does it play a role in the genesis of essential hypertension? Cardiovasc Res 18:455-462, 1984.

15. Randall OS: Effect of arterial compliance on systolic blood pres sure and cardiac function. Clin Exper Hypertens [A]4(7): 1045 1047,1982

16. Randall O, Esler M, Culp B, Julius S, Zweifler A: Determinants of baroreflex sensitivity in man. J Lab Clin Med 91:514-519, 1978.

17. Ferguson JJ, Julius S, Randall OS: Stroke volume-pulse pressure relationships in borderline hypertension: A possible indicator of decreased arterial compliance. J Hypertens 2(suppl 3):397-399, 1984.

18. Westerhof N, Elzinga G, Sipkema P: An artificial system for pumping hearts. J Appl Physiol 31:776-781, 1981.

19. Snedecor GW, Cochran WG: "Statistical Methods." Ames, Iowa: State University Press, 1967, pp 400-403.

20. Berne RM, Levy MN: The Arterial System. In: "Cardiovascular Physiology," 4th ed. London: The CV Mosby Company, 1981, 
pp 94-108.

21. van den Bos GC, Randall OS, Westerhof N: blood pressure and cardiac output during decreased arterial compliance. J Physiol (Lond)317:68P-69P, 1981 (abstract).

22. Roach MR, Burton AC: The effect of age on the elasticity of human iliac arteries. Can J Biochem Physiol 37:557-570, 1959.

23. Learoyd BM, Taylor MG: Alterations with age in the viscoelastic properties of human arterial walls. Circ Res 18:278-292, 1966.

24. Roach MR: The static elastic properties of carotid arteries from fetal sheep. Can J Physiol Pharmacol 48:695-708, 1970.

25. Cox RH, Jones AW, Swain ML: Mechanics and electrolyte composition of arterial smooth muscle in developing dogs. Am J Physiol 231:77-83, 1976.

26. Mirsky I, Janz RF: The effect of age on the wall stiffness of the human thoracic aorta: A large deformation "anisotropic" elastic analysis. J Theor Biol 59:467-484, 1976.
27. Pagani M, Mirsky I, Baig H, Manders WT, Kerkhof P, Vatner $S$ : Effects of age on aortic pressure-diameter and elastic stiffnessstress relationships in unanaesthetized sheep. Circ Res 44:420 429, 1979.

28. Myer WW: Funktionelle Morphologie des Gefabsystems im Kindesalter. Monatsschr Kinderheilkd 112:37-44, 1964.

29. Berry CL, Greenwald SE, Rivett SF: Static mechanical properties of the developing and mature rat aorta. Cardiovase Res 9:669-678, 1975.

30. Truswell AS, Kennedy BM, Hansen JDL, Lee RB: Blood pressures of ! Kung Bushmen in northern Botswana. Am Heart $J$ 84:5-12, 1972.

31. Remington JW, Noback CR, Hamilton WF, Gold JJ: Volume elasticity characteristics of the human aorta and prediction of the stroke volume from the pressure pulse. Am J Physiol 133:298$308,1948$. 